\title{
Assessment of environmental and health risks of arsenic in agricultural soils
}

\author{
C. Jones-Johansson ${ }^{1}$, M. Elert ${ }^{1}$, S. Vijayakumar ${ }^{1,2}$, P. Bhattacharya $^{2}$, I. Jordan ${ }^{3}$, \\ I. Mueller ${ }^{4}$, F. Battaglia-Brunet ${ }^{5}$ \& M.L. Guédard ${ }^{6}$ \\ ${ }^{1}$ Kemakta Konsult AB, Stockholm, Sweden \\ ${ }^{2}$ KTH-International Groundwater Arsenic Research Group, Department of Sustainable Development, \\ Environmental Science and Engineering, KTH Royal Institute of Technology, Stockholm, Sweden \\ ${ }^{3}$ G.E.O.S. Ingenieurgesellschaft $m b H$, Halsbrücke, Sachsen, Germany \\ ${ }^{4}$ Saxon State Office for Environment, Agriculture and Geology, Freiberg, Germany \\ ${ }^{5}$ BRGM, Orléans, France \\ ${ }^{6}$ LEB Aquitaine Transfert-ADERA, Villenave d'Ornon, France
}

\begin{abstract}
Within the framework of the AgriAs project, assessment of risks to health and the environment from arsenic in the agricultural soils and recipient water bodies is being carried out. Criteria for risk assessment from different organizations and countries have been collated, and an exposure model for arsenic in agricultural soils is being developed. The exposure model will be applied to assess the present-day situation at two test sites where elevated arsenic concentrations are found in agricultural soil. The model will also be used to assess the risk reduction achieved by proposed methods of amelioration and treatment.
\end{abstract}

\section{INTRODUCTION}

Arsenic (As) in agricultural soils, and its subsequent transport in the food chain and recipient waters potentially causes risks to human health (Murcott, 2012). Arsenic can accumulate in crop plants and high arsenic concentrations may also reduce crop yields. The present study, performed within the framework of the Water JPI AgriAs project, aims to develop tools for the risk assessment of arsenic in agricultural soils.

The risk assessment tools will be used to assess the risks at two test sites; one site is the former chemical ammunition destruction facility near Verdun, France, where arsenic-containing ammunition was destroyed in the inter-war period. The other site is located in Saxony, Germany, where mining and associated industries over a period of 800 years have led to elevated concentrations of arsenic in soils, groundwater and surface waters. Data from investigations at these sites about the speciation of arsenic and its bioavailability and ecotoxicity are being collected as part of the AgriAs project. The present-day situation will be studied and the effects of different methods of amelioration and treatments at these sites will be studied. The results of the work will be used in the development of guidelines for the sustainable management of the risks identified.

\section{METHODS}

\subsection{Collation of risk assessment criteria and site data}

Relevant criteria for use in health and environmental risk assessments of As in agricultural soils have been identified. The compiled criteria include toxicological reference values, limiting values for the concentrations of arsenic in different media through which exposure occurs (food, fodder and drinking water) and limit or guideline concentrations for arsenic in soils.

Data from the two test sites are also being compiled regarding concentrations of arsenic in soils, groundwater, surface water and plants.

Risk assessment has then been carried out by comparing measured concentrations in environmental media with the limit or guideline values.

\subsection{Development of an exposure model}

An exposure model for As in agricultural soils and water has been developed taking into account the main exposure pathways (Fig. 1).

The model can be adapted to different sites by using site-specific parameter values, especially in relation to the speciation of As and its effect on transport to and in groundwater, bioavailability and toxicity. The model than can be used in site-specific assessments of the risks from arsenic.

\section{RESULTS AND DISCUSSION}

Criteria for arsenic are not available for a comprehensive range of foodstuffs; at present criteria are available only for arsenic and one or two other groups of foodstuffs. In addition, criteria for arsenic in soil may lead to an overestimation of the risks from arsenic in agricultural soils as they do not take into account 


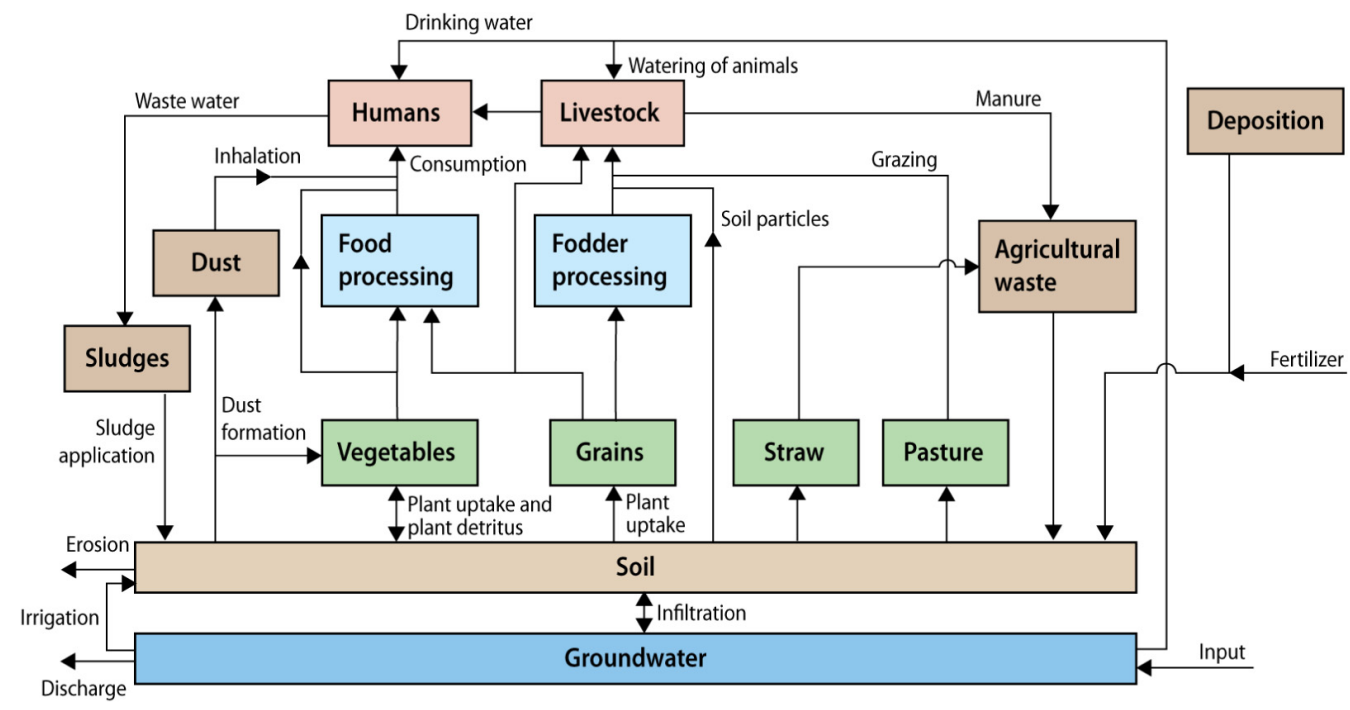

Figure 1. Conceptual exposure model for arsenic in agricultural soils.

site specific variations in bioavailability, mobility and uptake into the food chain.

The exposure model will be used for assessment of the present-day situation at the two field sites. The model will also be used to identify the major uncertainties regarding exposure to arsenic in agricultural soils and to identify areas where site specific data can improve exposure estimates. After calibration with site specific data, the model will be used to evaluate the risk reduction achieved by the proposed amelioration methods tested within the AgriAs project and the treatment methods developed and tested within the project. This information will be an important input for the development of recommendations for the sustainable management of risks from arsenic in agricultural soils.

\section{ACKNOWLEDGEMENTS}

AgriAs is co-funded by the EU and the Academy of Finland, L'Agence Nationale de la Recherche,
Bundesministerium für Ernährung und Landwirtschaft and Forskningsrådet FORMAS under the ERA-NET Cofund WaterWorks 2015 Call. This ERA-NET is an integral part of the 2016 Joint Activities developed by the Water Challenges for a Changing World Joint Programme Initiative (Water JPI).

\section{REFERENCES}

AgriAs. 2108. Collation of evaluation criteria for assessment of the risks from arsenic in agricultural soils (to be published).

Murcott S. 2012. Arsenic Contamination in the World: An International Sourcebook. IWA Publishing. London. 